\title{
GLYCINERGIC PATHWAYS IN THE GOLDFISH RETINA ${ }^{1}$
}

\author{
ROBERT E. MARC* AND DOMINIC MAN-KIT I.AM $\ddagger$ \\ * The University of Texas Sensory Sciences Center and Department of Ophthalmology, Houston. Texas 77025, and $\ddagger$ Cullen Eye Institute and \\ Program in Neuroscience, Baylor College of Medicine, Houston, Texas 77030)
}

\begin{abstract}
Autoradiographic localization of high affinity $\left[{ }^{3} \mathrm{H}\right]$ glycine uptake in the retina of the goldfish has been used to study some anatomical and physiological properties of potentially glycinergic neurons. There are two classes of retinal cells exhibiting high affinity glycine uptake: $\mathrm{A} a$ amacrine cells and $I 2$ interplexiform cells. A $a$ amacrine cells constitute about $20 \%$ of the somas in the amacrine cell layer and send their dendrites to the middle of the inner plexiform layer. There they are both pre- and postsynaptic primarily to other amacrine cells. Photic modulation of glycine uptake indicates that they are probably redhyperpolarizing/green-depolarizing neurons. $I 2$ interplexiform cells are a newly discovered type of interplexiform cell; in the outer plexiform layer, they receive direct synaptic input from the somas of reddominated GABAergic $\mathrm{H} 1$ horizontal cells and are apparently presynaptic to dendrites of unidentified types of horizontal cells. The connections of $I 2$ interplexiform cells have not been successfully characterized in the inner plexiform layer. These findings extend our knowledge of neurochemically specific pathways in the cyprinid retina and indicate that glycine, like GABA, is a neurotransmitter primarily involved with circuits coding "red" information.
\end{abstract}

The structural bases for brightness, color, form, and displacement coding are not well understood in any visual system, but combined intracellular recordings and dye injections in the retinas of cyprinid fishes show promise of identifying components of some of these coding networks. Even in cyprinid fishes, the diversities of neuronal morphologies and lack of precision in physiological classifications have led us to seek other ways to reduce uncertainties in structural-functional assignments. In this report, we describe part of our continuing studies of neuronal classification based on autoradiographic assessment of ${ }^{3} \mathrm{H}$ neurotransmitter uptake; in this case, $\left[{ }^{3} \mathrm{H}\right]-$ glycine uptake by goldfish retinal neurons.

Glycine is a plausible neurotransmitter candidate in the vertebrate nervous system. There is neurochemical (Aprison and Werman, 1965; Graham et al., 1967), morpholugical (Hökfelt and Ljungdahl, 1971; Matus and Dennison, 1972), and physiological evidence (Werman et al., 1967, 1968; Curtis et al., 1968) that glycine is an inhibitory transmitter released by interneurons onto motoneurons in the spinal ventral grey of the mammalian spinal cord (for a review, see Aprison and Nadi, 1978). Specific retinal interneurons could use glycine as a neurotransmitter.

Marc et al. (1978) reported that a subpopulation of amacrine cells $(\mathrm{ACs})^{2}$ in the goldfish retina exhibited

\footnotetext{
'This research was supported by National Institutes of Health Grants EY02576 (R. E. M.) and EY02423 (D. M. K. L.). We wish to thank Pat Glazebrook and Ric Summerall for histological assistance.

${ }^{2}$ The abbreviations used are: $\mathrm{A} a \mathrm{AC}$, type $a$ amacrine cell; $\mathrm{A} b \mathrm{AC}$, type $b$ amacrine cell; AC, amacrine cell; $\mathrm{BC}$, bipolar cell; C-type $\mathrm{HC}$,
}

selective accumulation of exogenously applied $\left[{ }^{3} \mathrm{H}\right] \mathrm{gly}-$ cine. The distribution of neuronal processes accumulating $\left[{ }^{3} \mathrm{H}\right]$ glycine was radically different from the pattern shown by $\gamma-\left[{ }^{3} \mathrm{H}\right]$ aminobutyric acid (GABA)-accumulating neurons, suggesting that investigations of the morphologies, responsivities, and connectivities of $\left[{ }^{3} \mathrm{H}\right] \mathrm{gly}-$ cine-labeled neurons could reveal important facets of photic processing in cyprinid retinas. We report now that $\left[{ }^{3} \mathrm{H}\right] \mathrm{glycine}$ is accumulated and released by two types of retinal neurons which we have tentatively designated type $\mathrm{A} a \mathrm{ACs}$ and type $I 2$ interplexiform cells (IPCs). Most, if not all, of the Aa ACs appear to be red-hyperpolarizing/green-depolarizing and are both pre- and postsynaptic to other ACs located primarily in sublamina $a$

color opponent horizontal cell, e.g., $\mathrm{H} 2 \mathrm{HC}$; distal, physically closer to the photoreceptor layer; $\mathrm{EHC}$, external horizontal cell, equivalent to H1 HC; EM-ARG, electron microscope autoradiograph; EPSP, excitatory postsynaptic potential; GABA, $\gamma$-aminobutyric acid; GC, ganglion cell; $\mathrm{HC}$, horizontal cell; $\mathrm{HI} \mathrm{HC}$, type $\mathrm{Hl}$ spectrally monophasic horizontal cell; H2 HC, type H2 spectrally biphasic horizontal cell; INL, inner nuclear layer; IPC, interplexiform cell; $I 1$ IPC, type $I 1$ dopaminergic interplexiform cell; $I 2$ IPC, type $I 2$ glycinergic interplexiform cell; IPL, inner plexiform layer; LM-ARG, light microscope autoradiograph; L-type $\mathrm{HC}$, noncolor opponent horizontal cell, i.e., $\mathrm{H} 1 \mathrm{HC} ; \mathrm{Ma}$ $\mathrm{BC}$, type $\alpha$, mixed rod-cone, center-hyperpolarizing bipolar cell; $\mathrm{M} b$ $\mathrm{BC}$, type $b$, mixed rod-cone, center-depolarizing bipolar cell; OPL, outer plexiform layer; proximal, physically closer to the ganglion cell layer; $\mathrm{PSP}$, postsynaptic potential; +R/-G, red-depolarizing/green-hyperpolarizing cells; $-\mathrm{R} /+\mathrm{G}$, red-hyperpolarizing/green-depolarizing cells; sublamina $a$, distal half of the inner plexiform layer; sublamina $b$, proximal half of the inner plexiform layer. 
of the inner plexiform layer (IPL). I2 IPCs are apparently presynaptic to unidentified horizontal cell $(\mathrm{HC})$ dendrites in the outer plexiform layer (OPL) and postsynaptic to the somas of type H1 HCs.

\section{Materials and Methods}

Uptake experiments. Retinas were analyzed for $\left[{ }^{3} \mathrm{H}\right]-$ glycine uptake autoradiographically. Common and comet varieties of Carassius auratus ( $>12 \mathrm{~cm}$ standard length) were maintained in a communal aquarium and were dark adapted at least $3 \mathrm{hr}$ before dissection. Animals were killed by cervical transection and pithing, eyes were enucleated, and retinas were removed under visualization with infrared image converters. For the investigation of light-evoked changes in uptake, each retina was halved or quartered and each part was incubated for $10 \mathrm{~min}$ in a $25-\mu \mathrm{l}$ droplet of saline $\left./{ }^{3} \mathrm{H}\right]$ glycine medium in a sealed chamber with $100 \%$ oxygen flowing over the droplets. The saline was as described in Marc et al. (1978). [ $\left.{ }^{3} \mathrm{H}\right]$ Glycine was obtained from New England Nuclear, dried in a flash evaporator, then redissolved in saline to obtain various activities. Most experiments used $100 \mu \mathrm{Ci} / \mathrm{ml}$ of $\left[{ }^{3} \mathrm{H}\right.$ ]glycine $(=6 \mu \mathrm{M}$ glycine $)$, but activities up to $500 \mu \mathrm{Ci} /$ ml were employed to obtain preparations with conveniently short exposure times for electron microscope autoradiography. Chin and Lam (1980) have shown that there are two uptake systems for glycine in the goldfish retina: (1) a high affinity system with an apparent $K_{m}$ of $8.1 \mu \mathrm{M}$ and $V_{\max }$ of $9.1 \mathrm{pmol} \cdot \mathrm{min}^{-1} \cdot \mathrm{mg}$ of protein ${ }^{-1} ;(2)$ a low affinity system with an apparent $K_{m}$ of $630 \mu \mathrm{M}$ and $V_{\max }$ of $430 \mathrm{pmol} \cdot \mathrm{min}^{-1} \cdot \mathrm{mg}$ of protein ${ }^{-1}$. The low affinity system is competitively inhibited by amino acids transported by the type A neutral amino acid transport system, e.g., serine and alanine (see Oxender and Christenson, 1963). The high affinity system is unaffected by these amino acids, and glycine uptake under neutral amino acid competition is limited to the two classes of neurons which we will discuss in this paper.

Retinas or retinal pieces were stimulated with constant or $2-\mathrm{Hz}$ square wave stimuli at wavelengths of 650,530 , or $500 \mathrm{~nm}$. Quantal fluxes were measured with an E. G. \& G. radiometer in the position of the retina. Flux densities were adjusted to range from darkness up to $1 \times 10^{1}$ quanta $\cdot \mathrm{sec}^{-1} \cdot \mu \mathrm{m}^{-2}$; most experiments employed matched 650- and 500-nm lights $\left(1 \times 10^{4}\right.$ quanta $\cdot \mathrm{sec}^{-1}$. $\left.\mu \mathrm{m}^{-2}\right)$. Statistically significant alterations in $\left[{ }^{3} \mathrm{H}\right]$ glycine uptake were obtained with these procedures.

After incubation, retinas were fixed in $1 \%$ paraformaldehyde, $2.5 \%$ glutaraldehyde, $3 \%$ sucrose, $0.01 \% \mathrm{CaCl}_{2}$ in $80 \mathrm{~mm}$ sodium cacodylate buffer $(\mathrm{pH} 7.4)$ for $15 \mathrm{~min}$ at room temperature and overnight at $4^{\circ} \mathrm{C}$. Specimens were postfixed in $1 \% \mathrm{OsO}_{4}$ in cacodylate buffer and sometimes stained en bloc with $1 \%$ uranyl acetate in maleate buffer. Tissues were dehydrated in cold graded methanols and acetone, followed by embedment in a soft Epon mixture (Stell and Lightfoot, 1975).

Release experiments. Release of accumulated $\left[{ }^{3} \mathrm{H}\right] \mathrm{gly}-$ cine was evaluated by loading pieces of retina with $\left[{ }^{3} \mathrm{H}\right]$ glycine and subsequently incubating the pieces in unlabeled salines. Pieces were incubated for $10 \mathrm{~min}$ in red light in the standard oxygenated $\left[{ }^{3} \mathrm{H}\right]$ glycine medium for loading and postincubated for $10 \mathrm{~min}$ in regular saline,
$40 \mathrm{mM} \mathrm{K}^{+}$(exchanged for $\mathrm{Na}^{+}$) saline, or $40 \mathrm{~mm} \mathrm{~K} \mathrm{~K}^{+}, 5$ $\mathrm{mm} \mathrm{Co}{ }^{2+}$ saline. Three sets of experiments were performed; fixation and processing were as previously described.

Histology. Ribbons of $0.5-\mu \mathrm{m}$ sections were floated onto beads of distilled water on clean glass slides and dried at $85^{\circ} \mathrm{C}$. The slides were coated with a $50 \%$ aqueous solution of Kodak NTB-2 emulsion and exposed at $4^{\circ} \mathrm{C}$ for 1 day to 2 weeks for various purposes. Light microscope autoradiographs (LM-ARGs) were developed at $17^{\circ} \mathrm{C}$ in full strength filtered Dektol and stained with toluidine blue when desired. Thin sections for electron microscopy were placed on Formvar-coated grids or celloidin-coated slides. Specimens were stained with lead citrate after uranyl acetate and finally were carbon coated. For electron microscope autoradiographs (EMARGs), grids were coated with diluted Ilford L-4 emulsion by a loop method; slides were coated as described in Bok and Young (1972). The preparations were exposed from 2 weeks to 3 months and developed with either phenidone or Kodak D-19.

Light microscopy and grain quantitation. Light microscopy was performed primarily with $\times 25$ and $\times 40$ (oil) planapochromatic objectives. Panchromatic and high-contrast $35-\mathrm{mm}$ films were used for photomicrography. Grain densities in unstained sections were measured photometrically with a photomultiplier tube using a $4-\mu \mathrm{m}$ viewing aperture in either the reflectance mode or densitometric mode depending on the range of grain densities to be measured in a given set of experiments. These optical measures were converted to grain densities with empirically determined calibration curves.

Terminology. There are three aspects of morphological notation which need to be clarified. First, we arbitrarily divide the IPL into two sublaminas of equal thickness, following the scheme of Famiglietti et al. (1977). Sublamina $a$ is the distal layer and sublamina $b$ is the proximal layer. Undoubtedly, truly diagnostic functional and morphological grounds will eventually emerge and permit a realistic characterization of sublamination in the IPL. As it stands, we know that functional sublamination exists, but the morphological limits and overlaps of sublaminas $a$ and $b$ are presently unknown. The terminology is therefore qualitative.

Second, we refer to the glycine-accumulating ACs as type $\mathrm{A} a \mathrm{ACs}$. This is meant to indicate that the primary zone of arborization of the cells is in what we have arbitrarily denoted sublamina $a$. There is clear overlap of the arborization into sublamina $b$. Since the $a$ versus $b$ dichotomy is, at present, a functional one whose anatomical limits are incompletely defined, we have chosen merely to indicate the zone in which most of the arborization occurs. With further investigation, we will clearly require a refinement of classificatory schemes for both ACs and sublaminations of the IPL. The present terminologies are useful conveniences only.

Finally, we characterize a cell that is similar in shape and position, though not in size, to the small stellate cell of perch retina (Ramón y Cajal, 1892). We shall refer to these cells as interplexiform cells (IPCs). This is based on the rationale that a neuron which connects the outer and inner plexiform layers but does not contact photo- 
receptor cells is an "inter-plexiform cell" (see Gallego, 1971). The point of this definition is to recognize that the well characterized goldfish dopaminergic IPC is not necessarily archetypal for all the possible kinds of IPCs in the retinas of diverse species.

\section{Results}

Aa amacrine cells. In the amacrine cell layer, a large population of neurons with small somas exhibits preferential accumulation of $\left[{ }^{3} \mathrm{H}\right]$ glycine. Glycine-accumulating cells ( $\mathrm{A} a \mathrm{ACs}$ ) account for $20 \pm 4 \%$ (mean \pm standard deviation) of the somas in the AC layer as determined by counts from horizontal section autoradiographs (2674 somas counted). The AC layer is defined as all cells on the distal border of the IPL, which undoubtedly includes some bipolar cells (BCs). The density of glycine-accumulating ACs is about 3500 cells $/ \mathrm{mm}^{2}$. The somas are small ( 5 to $7 \mu \mathrm{m}$ in diameter) and generally spherical or slightly prolate. Some cells are deformed by compaction against their neighbors. A dense band of label occupies the proximal portion of sublamina $a$ and overlaps into sublamina $b$ (Fig. 1). In fortuitous sections, somas can be seen to be connected with the labeled band by a single slender stalk (Fig. 2). A significant feature of the dendritic arbor is that a label-free band exists beneath the soma layer. A different class of neurons, apparently containing an indoleamine, ramifies in that layer (Marc, 1980). The labeled band of $\mathrm{A} a \mathrm{AC}$ dendrites appears to be a dense aggregation of terminal swellings in which there does occur some weak stratification (Figs. 1 and 3).

We are not certain yet that all glycine-accumulating neurons in the AC layer are of the same functional class. Horizontal sections through the AC layer give the impression that glycine-accumulating cells are all quite similar in size and this is borne out by our measurements of soma dimensions, where no significant morphological subdivisions of glycine-accumulating cells have been detected. Furthermore, the impression that each soma gives rise to a single proximal dendrite can only be supported by serial section autoradiographs of many labeled neurons. We have not completed the effort, but no exceptions have been identified.

Stimulus modulation of glycine uptake has provided some evidence of homogeneity within the population of A $a$ ACs. Changes in uptake were evoked by exposing isolated retinas to colored lights during a $10-\mathrm{min}$ incubation in a saline containing $100 \mu \mathrm{Ci} / \mathrm{ml}$ of $\left[{ }^{3} \mathrm{H}\right]$ glycine ( $\simeq 6 \mu \mathrm{M}$ glycine). Autoradiographs for quantitative microphotometry were exposed for 7 days and those for morphological purposes were exposed for 14 days. The five stimulus conditions were: (1) darkness; (2) red light (1 $\times 10^{4}$ quanta $\left.\cdot \mathrm{sec}^{-1} \cdot \mu \mathrm{m}^{-2}, 650 \mathrm{~nm}\right) ;(3)$ "dim" red light (1 $\times 10^{3}$ quanta.sec $\left.{ }^{1} \cdot \mu \mathrm{m}^{2}, 650 \mathrm{~nm}\right) ;(4)$ green light $(1 \times$ $10^{4}$ quanta $\cdot \mathrm{sec}^{-1} \cdot \mu \mathrm{m}^{-2}, 500 \mathrm{~nm}$ ); and (5) dim red light added to green light. The lights were constant or flickered with a $2-\mathrm{Hz}$ square wave. In the dim red + green light condition, the lights were flickered $90^{\circ}$ out of phase. The results are summarized in Figures 4 to 6 .

Red lights enhanced labeling while green lights or darkness elicited low levels of uptake. If the relation between membrane potential and observed uptake holds for glycine as well as GABA (Marc et al., 1978), our results imply that $\mathrm{A} a \mathrm{ACs}$ are hyperpolarized by long wavelength lights. Experiments with $1 \times 10^{4}$ quanta. $\mathrm{sec}^{-1} \cdot \mu \mathrm{m}^{-2}$ of red light showed the most uptake, while green lights of equal quantal flux did not exhibit uptake much different from darkness (Figs. $4 a$ and $5 b$ ). The failure of green light to modulate uptake detectably from the dark level could have been due to a lack of greenhyperpolarizing input or perhaps that green lights actually depolarize the cells somewhat. By combining dim red light and green light, we found that green light actually suppresses red light-induced uptake (Figs. $4 b$ and 5a). This implies that most $\mathrm{A} a \mathrm{ACs}$ receive redhyperpolarizing and some green-depolarizing inputs. Quantitative results from $29\left[{ }^{3} \mathrm{H}\right]$ glycine experiments are summarized in Figure 6. The responses of $\mathrm{A} a$ ACs to flickering and constant lights were not distinguishable.

Treatment of [ $\left.{ }^{3} \mathrm{H}\right]$ glycine-loaded retinas with high potassium salines leads to about $40 \%$ loss of somatic label and massive losses from labeled terminals (Figs. 6 and 7), in accord with the recent findings of Chin and Lam (1980). This apparent release is partially blocked by the presence of excess cobalt ions.

The potassium-evoked loss of somatic label is not necessarily evidence of neurotransmitter release, for we do not know what other events transpire at the somatic level that might cause leakage of labeled material upon depolarization. Photometry of the somas is, however, the only purely quantitative assessment that we can make at this time. Loss of labeled terminals with potassium treatment is qualitatively much more convincing (Fig. 7) since we expect the terminal to (1) release its neurotransmitter and (2) suppress uptake in response to depolarization. Concomitant cobalt and potassium results are equivocal, with some qualitative retention of terminals. Prewashing for $5 \mathrm{~min}$ with $5 \mathrm{~mm}$ cobalt solutions will fully block potassium-evoked release but leads to very poor morphological preservation. All things considered, morphometric assessment of bona fide neurotransmitters release remains very difficult to interpret.

Attempts to characterize the circuitry of Aa ACs have met with limited success because the cells engage primarily in synapses with other ACs, the identities of which are unknown. Furthermore, A $a$ ACs could be presynaptic to ganglion cell (GC) dendrites since unidentified, pale, microtubule-containing profiles sometimes are found opposite $\mathrm{A} a \mathrm{AC}$ presynaptic specializations. A complication with this interpretation is that apparent GC dendrites and certain AC processes in sublamina $a$ are difficult to distinguish when the latter fail to demonstrate synaptic vesicles. Finally, $\mathrm{A} a \mathrm{ACs}$ are infrequently presynaptic to axon terminals of unidentified BCs. Until these vague associations are clarified, the involvement of $\mathrm{A} a \mathrm{ACs}$ in specific circuits remains speculative.

Ultrastructurally, Aa ACs possess small, sometimes closely packed somas (Fig. 8). The cytoplasm is mildly electron dense and contains much glycogen; the nucleus is pale and takes up 50 to $75 \%$ of the volume of the soma. The glycogen appears in the proximal stalk and dendritic processes as well, which may facilitate identification in non-autoradiographic preparations. The cytoplasmic electron density and glycogen content may also aid in 

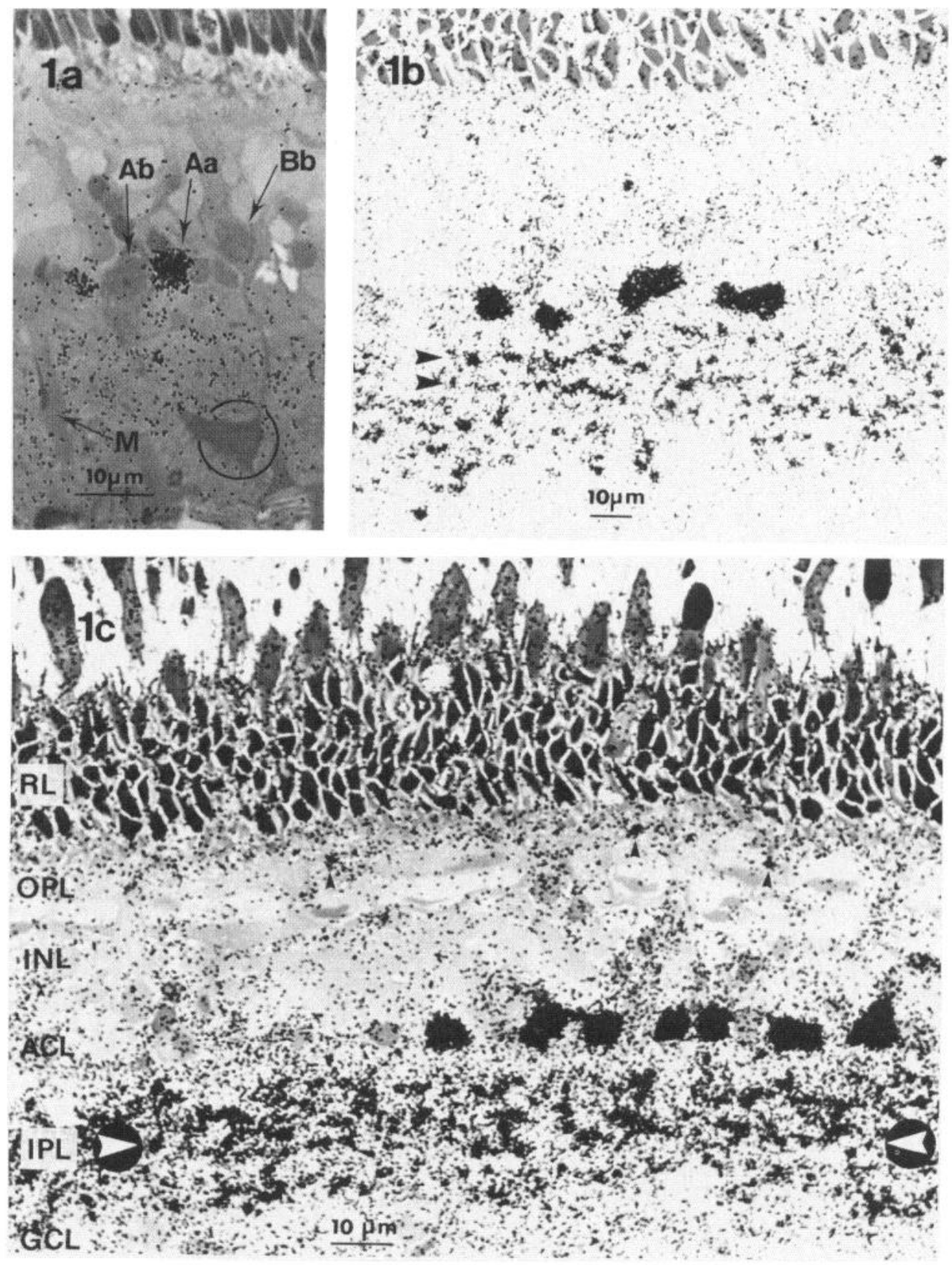

Figure 1. [ $\left.{ }^{3} \mathrm{H}\right]$ Glycine uptake in the goldfish retina (LM-ARGs). $a$, A comparison between the shape of glycine-accumulating $\mathrm{A} a \mathrm{ACs}(A a)$ and the shapes of nonlabeled cells: center-depolarizing $\mathrm{BCs}(B b)$, an AC resembling GABAergic A $b \mathrm{ACs}(A b)$, and part of a Müller's cell $(M)$. The label in the IPL is diffuse and shows little structure. The circled element is the B $b$ BC axon terminal. Seven-day exposure. $b$, Possible laminar arrangements of A $a$ AC dendrites are indicated by arrows. A few heavily labeled somas are separated from their arbors by a distinct gap. Fourteen-day exposure. $c$, A cluster of eight to 10 A $a$ ACs clearly defines the gap between their somas and arbors. The dendritic arbors dominate the central portion of the IPL with some overlap into sublamina $b$. Sublamina $a$ is that part of the IPL above the imaginary line indicated by the white arrows; sublamina $b$ is below that line. Small black arrows indicate terminals of glycine-accumulating I2 IPCs. Background label is due to low affinity uptake. Twenty-one-day exposure. $A C L$, amacrine cell layer; $G C L$, ganglion cell layer; $R L$, receptor layer.

interpreting synapses involving $\mathrm{A} a$ ACs because the terminals of glycine-accumulating I2 IPCs in the OPL, at least, are electron lucent and glycogen poor.

As expected, little label is found in the zone just beneath the somas. No synaptic inputs onto or from the single proximal dendrites or "stalks" of A $a$ ACs have been seen. In mid-IPL $\left[{ }^{3} \mathrm{H}\right]$ glycine-labeled profiles are found to be presynaptic to processes that we presume to be ACs (Fig. 9a) based on the observation that similar electron-lucent profiles are presynaptic to labeled $\mathrm{A} a \mathrm{AC}$ profiles (Fig. 9b). That $\mathrm{A} a \mathrm{ACs}$ are presynaptic to ACs is confirmed in Figure 10, where a reciprocal synaptic arrangement is shown. Once more, the presumed $\mathrm{AC}$ is electron lucent. We do not know if more than one type 

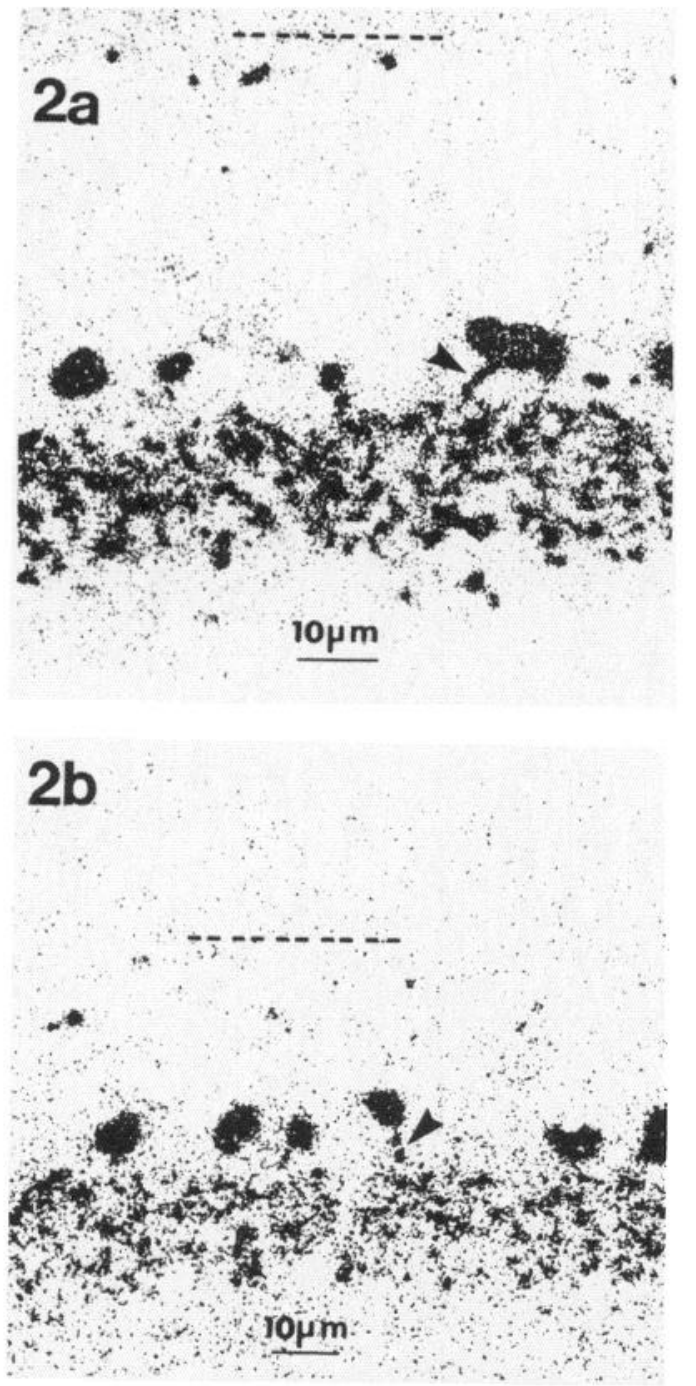

Figure 2. Proximal dendritic stalks of Aa ACs (LM-ARGs). As far as can be determined, each A $a \mathrm{AC}$ has only one proximal stalk (arrows) though some are obliquely directed. The dashed line indicates the proximal border of the cone pedicles. $a$, Retina incubated at $100 \mu \mathrm{Ci} \mathrm{ml} \mathrm{m}^{-1}$, exposed $=6$ months. $b$, Retina incubated at $500 \mu \mathrm{Ci} \mathrm{ml}{ }^{-1}$, exposed 14 days.

of $\mathrm{AC}$ interacts with $\mathrm{A} a \mathrm{ACs}$ nor can we exclude $\mathrm{A} a \mathrm{AC}$ synapses onto GCs. The exchange of conventional synapses by $\mathrm{A} a$ ACs in sublamina $a$ probably does not involve any IPCs because (1) dopaminergic IPCs make most of their connections in deep sublamina $b$ (Marc, 1980 ; R. E. Marc, manuscript in preparation) and (2) glycine-accumulating IPCs would be labeled.

On very rare occasions, $\mathrm{A} a \mathrm{ACs}$ make conventional synapses upon the axon terminals of BCs in sublamina $a$ (Fig. 11). An impression that Aa ACs were pre- and postsynaptic to $\mathrm{Ma} \mathrm{BCs}$ (center-hyperpolarizing $\mathrm{BCs}$ ) was reported earlier by Marc (1980). In more extensive observations, all $\mathrm{A} a \mathrm{AC} \rightarrow \mathrm{BC}$ synapses have been onto small or moderate sized BC terminals and clearly not onto Ma BCs. To date, $13 \mathrm{M} a \mathrm{BC}$ terminals have been analyzed; labeled profiles often approach the terminals, sometimes near the synaptic ribbon, but no clear syn- apses have been identified. It is probable that most, if not all, $\mathrm{A} a \mathrm{AC} \rightarrow \mathrm{BC}$ synapses involve cone $\mathrm{BCs}$ and not the mixed rod-cone $\mathrm{M} a \mathrm{BCs}$. Labeled terminals never contact $\mathrm{M} b \mathrm{BCs}$ (center-depolarizing BCs) in sublamina $b$, nor do we find contacts with putative cone BCs in sublamina $b$.

I2 interplexiform cells. Dowling and Ehinger (1975, 1978) have described the circuitry of a class of dopaminergic interplexiform cells (IPCs) with inputs arising in the IPL and outputs onto BCs and HCs in OPL. We have designated these neurons type I1 IPCs to distinguish them from a new class of IPCs: glycine-accumulating $I 2$ IPCs. $\left[{ }^{3} \mathrm{H}\right]$ Glycine-labeled $I 2$ IPC somas are found in the middle to proximal third of the inner nuclear layer (INL) among the somas of BCs (Fig. 12). They are generally large (10 to $12 \mu \mathrm{m}$ in diameter) and of irregular profile, appearing spherical, ovoid, or prolate in single sections. I2 IPCs are relatively rare cells with an apparent density of 25 cells $/ \mathrm{mm}^{2}(N=125)$. The description of their morphology thus relies on an aggregate of images obtained from many serial sections; diagnostic sections are indeed fortuitous. Figures 12 to 14 are collections of autoradiographs for over 2000 sections.

The principal features of I2 IPCs are that large, ropelike dendrites arise from the soma, usually in pairs, and course obliquely toward the OPL, branching infrequently en route and finally terminating in the OPL (Fig. 13). The terminals stratify narrowly within the OPL just distal to the somas of $\mathrm{H} 1 \mathrm{HCs}$ and just proximal to the cone pedicles. The terminals are rather infrequent; we estimate their density less than $1 \times 10^{4} / \mathrm{mm}^{2}$ or about five terminals per H1 HC. I2 IPCs connect with the IPL by processes which arise from the dendritic arbor in the

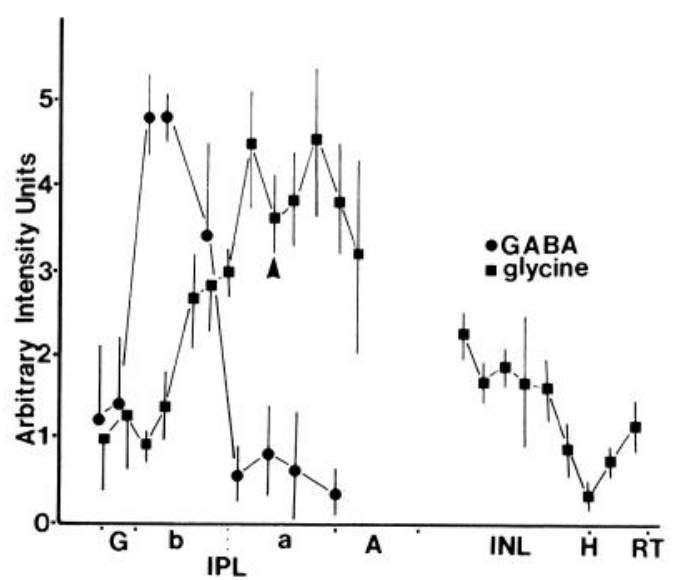

Figure 3. Radial density of GABA and glycine uptake in ACs and I2 IPCs. Retinas were incubated as described under "Materials and Methods." Density in arbitrary units was measured with a photomultiplier in the microreflectance mode. Each point is the mean of individual measurements from four retinal sites \pm 1 standard deviation. GABA uptake is maximal just above the ganglion cell layer $(G)$ in sublamina $b$ of the IPL and corresponds to the dendritic arbor of A $b$ ACS (Marc et al., 1978). Glycine uptake is maximal in sublamina $a$, possesses a dip in density at mid-IPL (arrow) and overlaps well into sublamina $b$. Glycine uptake reaches a minimum near the horizontal cell layer $(H)$ with a small secondary rise in the OPL near the photoreceptor terminals $(R T) . A$, amacrine cell layer. 

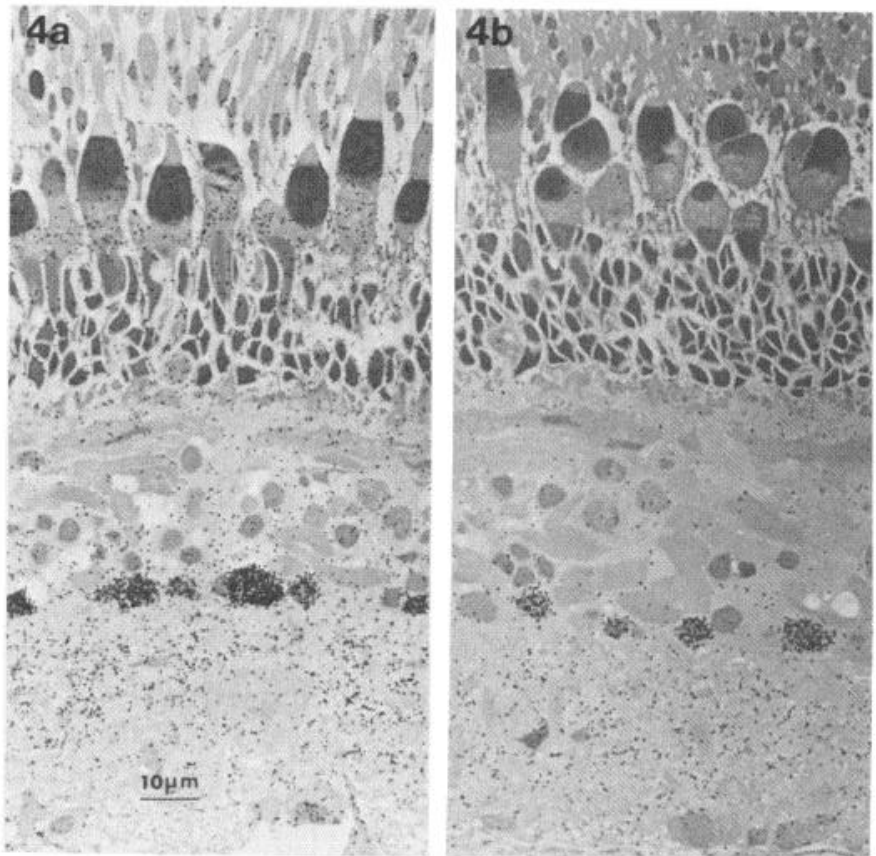

Figure 4. Red light modulation of glycine uptake (LMARGs). Incubation conditions are described under "Materials and Methods." All preparations in Figures 4 and 5 were from a single retina. Fourteen-day exposures; $2-\mathrm{Hz}$ square wave flicker. $a, 1 \times 10^{4}$ quanta $\cdot \mathrm{sec}^{-1} \cdot \mu \mathrm{m}^{-2}, 650 \mathrm{~nm} . b, 1 \times 10^{3}$ quanta $\cdot \mathrm{sec}^{-1}$. $\mu \mathrm{m}^{-2}, 650 \mathrm{~nm}$.

INL and drop rather directly through the AC layer into the IPL (Fig. 14).

Viewed in EM-ARGs, the only processes that were associated reliably with silver grains within the OPL were typically very electron lucent with few organelles. We presume these to be processes from I2 IPCs; the terminals frequently appear overextracted or osmotically damaged. As I2 IPC processes course through the distal layer of $\mathrm{HCs}$, they receive conventional synapses from the somas of H1 HCs (Fig. 15). The synapses are rare, contain few vesicles, and are typically $200 \mathrm{~nm}$ in lateral extent. Within the OPL, we have identified a single case where an I2 IPC process may be presynaptic to an unidentified HC dendrite (Fig. 16). In support of this interpretation, we note that Rayborn et al. (1980) have clearly identified conventional synapses from $\left[{ }^{3} \mathrm{H}\right]$ glycine-labeled profiles onto HCs in the OPL of the African clawed frog, Xenopus laevis. We must stress that our characterization of the $I 2$ IPC synapse onto $\mathrm{HCs}$ is tentative.

A comparison of I1 IPCs with I2 IPCs serves to summarize the major architectural features of each cell type. The somas of dopamine-accumulating I1 IPCs are always found in the AC layer bordering the IPL, but I2 IPC somas are located within the INL. The major dendrites arising from I1 IPC somas are directed toward the IPL and terminate predominantly in sublamina $b$; the major dendrites of I2 IPCs course toward the OPL and terminate in the OPL proper. The I1 IPCs possess a dense and rather broad terminal field in the OPL which connects to the dendritic arbor in the IPL via rarely occurring thin ascending processes (see Ehinger et al., 1969; Dowling
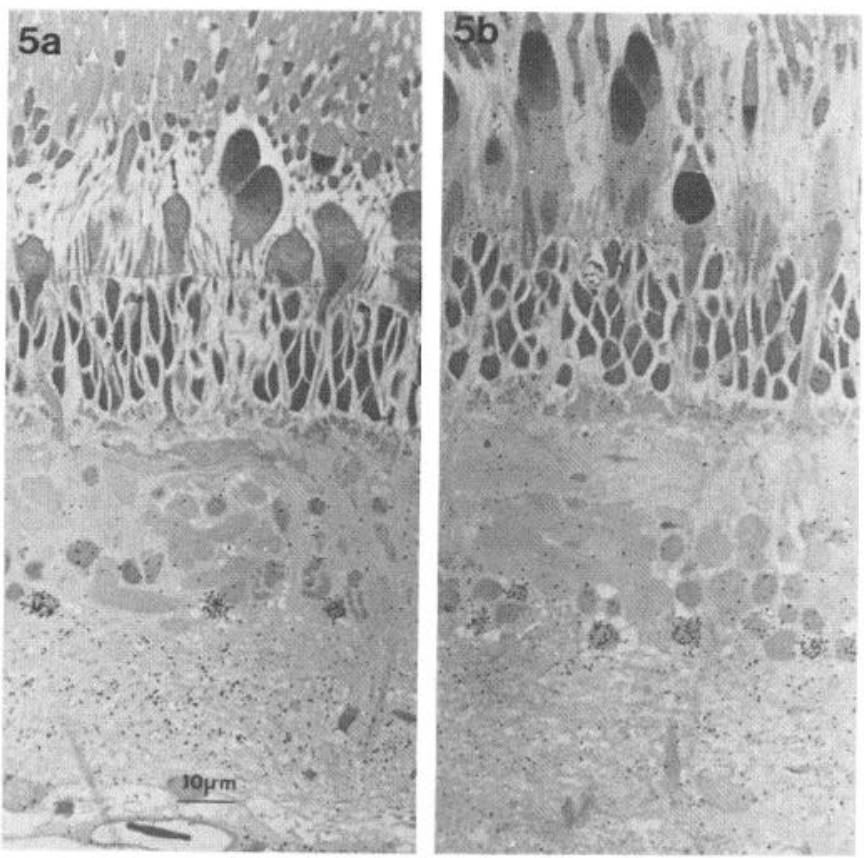

Figure 5. Green light modulation of glycine uptake (LMARGs). Conditions were as in Figure 4. $a, 1 \times 10^{4}$ quanta $\cdot$ sec $^{-1}$. $\mu \mathrm{m}^{-2}, 500 \mathrm{~nm}$ added to $1 \times 10^{3}$ quanta $\cdot \mathrm{sec}^{-1} \cdot \mu \mathrm{m}^{-2}, 650 \mathrm{~nm} . b$. $1 \times 10^{4}$ quanta $\cdot \mathrm{sec}^{-1} \cdot \mu \mathrm{m}^{-2}, 500 \mathrm{~nm}$.

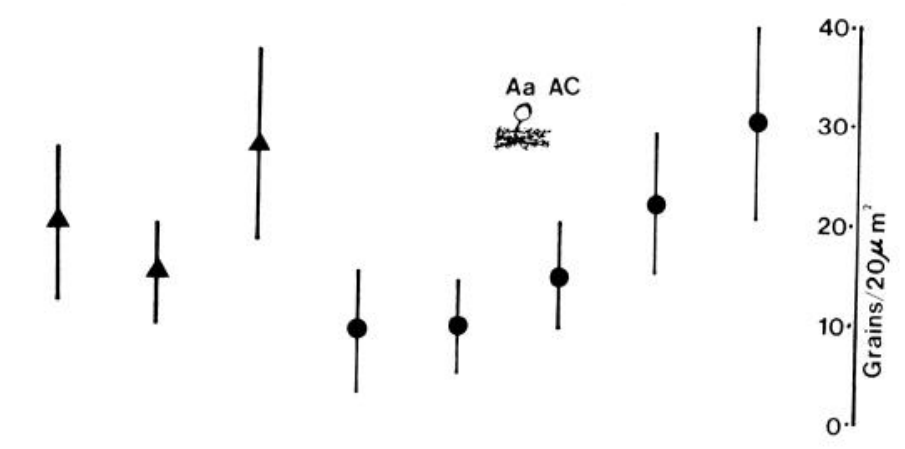

$\begin{array}{llllllllll}\mathrm{K}^{+}+\mathrm{Co}^{++} & \mathrm{K}^{+} & \mathrm{S} & \mathrm{D} & \mathrm{G} & \mathrm{G}+\mathrm{r} & \mathrm{r} & \mathrm{R}\end{array}$

Figure 6. Summary of light and ionic manipulations of glycine uptake in $\mathrm{Aa}$ AC somas. Grain densities were determined with a photomultiplier in the microdensitometric mode and a 4- $\mu \mathrm{m}$ diameter aperture; 7 -day exposures. While 7-day exposures are easier to quantify microscopically, photomicrographs are all shown as 14-day exposures or longer because they are more visually interpretable. Each point is the mean of all cells measured in each of several experiments \pm 1 standard deviation. The number of experiments and cells measured follows the description of each experiment. The light exposure experiments were performed as described under "Materials and Methods": $R, 1 \times 10^{4}$ quanta $\cdot \mathrm{sec}^{-1} \cdot \mu \mathrm{m}^{-2}, 650 \mathrm{~nm}$ (six experiments, 79 cells). $r, 1 \times 10^{3}$ quanta $\cdot \mathrm{sec}^{-1} \cdot \mu \mathrm{m}^{-2}, 650 \mathrm{~nm}$ (three experiments, 30 cells). $G+r, 1 \times 10^{4}$ quanta $\cdot \sec ^{-1} \cdot \mu \mathrm{m}^{-2}, 500 \mathrm{~nm}+1 \times 10^{3}$ quanta $\cdot \mathrm{sec}^{-1} \cdot \mu \mathrm{m}^{-2}, 650 \mathrm{~nm}$ (three experiments, 30 cells). $G, 1$ $\times 10^{4}$ quanta $\cdot \mathrm{sec}^{-1} \cdot \mu \mathrm{m}^{-2}, 500 \mathrm{~nm}$ (three experiments, 30 cells). $D$, darkness (five experiments, 50 cells). Ionic release experiments were performed as described under "Materials and Methods": $S$, physiological saline washout (three experiments, 45 cells). $K^{+}, 40 \mathrm{~mm} \mathrm{~K} \mathrm{~K}^{+}$saline washout (three experiments, 30 cells). $\mathrm{K}^{+}+\mathrm{Co}^{++}, 40 \mathrm{~mm} \mathrm{~K}^{+}+5 \mathrm{~mm} \mathrm{Co}^{2+}$ saline washout (three experiments, 30 cells). 

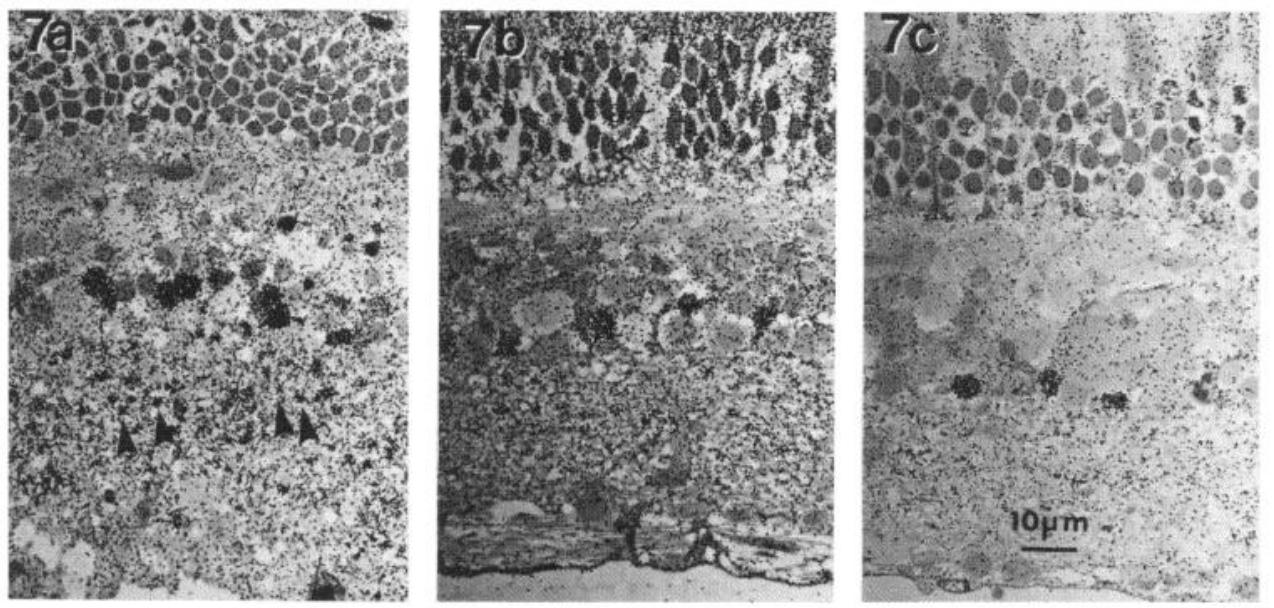

Figure 7. Potassium-evoked release of label (LM-ARGs). All preparations in this figure are from a single retina, incubated as described under "Materials and Methods." $a$, Saline washout. Arrows indicate the retention of dense terminal clusters characteristic of Aa ACs. $b, 40 \mathrm{~mm} \mathrm{~K}^{+}+5 \mathrm{~mm} \mathrm{Co}^{2+}$ saline washout. While there is distinct loss of label, some terminal clustering is preserved. $c, 40 \mathrm{~mm} \mathrm{~K}^{+}$saline washout. There is a heavy loss of terminal labeling and about $40 \%$ loss in somatic label density (see Fig. 6).

and Ehinger, 1978). The interconnection of OPL and IPL arbors in I2 IPCs is made by way of infrequent processes which descend from the larger caliber dendrites in OPL toward the IPL.

So far I2 IPCs have been refractory to modulation of uptake, exhibiting no clear variation of labeling as a function of light exposure. Either we have failed to select appropriate stimuli or the somas of I2 IPCs are not sensitive indicators of events occurring at synaptic terminals.

\section{Discussion}

Glycine uptake as contributory evidence for transmitter identification. Assays of neurotransmitter identity may include evidence of presynaptic accumulation by uptake and/or synthesis, endogenous content, or evoked release; evidence of postsynaptic action; and a mechanism for rapid inactivation. We have established previously that GABA fulfills many of these requirements in goldfish H1 HCs: H1 HCs have a powerful GABA uptake system (Lam and Steinman, 1971; Marc et al., 1978), contain glutamic acid decarboxylase (Lam et al., 1979), can synthesize GABA from glutamic acid (Lam, 1975), and will release GABA with physiological stimulation (Marc et al., 1978). Furthermore, there is now excellent electrophysiological evidence that GABA is the transmitter in a feedback synapse between $\mathrm{H} 1 \mathrm{HCs}$ and cones in teleost fishes (Lam et al., 1978; Murakami et al., 1978; Wu and Dowling, 1980).

Glycine is a problematic candidate since it is used metabolically by all cells. No mechanisms of glycine synthesis or degradation unique to "glycinergic" neurons have been identified satisfactorily (see Aprison and Nadi, 1978 for a brief review). The most compelling evidence for glycine as a transmitter comes from several pharmacological investigations of inhibitory postsynaptic potentials (IPSPs) in medullary reticular neurons (e.g., Tebécis and DiMaria, 1972; Matthews and Wickelgren, 1979). Of these studies, the most recent demonstrate that glycine adequately mimics an endogenous transmitter mediating some IPSPs in lamprey medullary Müller cells: Glycineinduced hyperpolarizations possess the same reversal potential and ionic dependence $\left(\mathrm{Cl}^{-}\right)$as the natural IPSP; both glycine-induced hyperpolarizations and the natural IPSPs are blocked by strychnine (Matthews and Wickelgren, 1979; Martin, 1979).

Such pharmacological characterizations have yet to be performed in retina, though there have been studies of glycinergic influences. Unfortunately, none of the previous evidences contribute to a morphological identification of glycinergic neurons. Because of the limited amount of correlative data available, we must evaluate the validity of high affinity glycine uptake as evidence of a neurotransmitter system.

Uptake has been proposed as a mechanism for clearance of neurotransmitter from the synaptic cleft (e.g., Iversen, 1971). If so, conditions which suppress uptake should prolong evoked postsynaptic potentials (PSPs). This appears to be the case in (1) a serotoninergic synapse in Aplysia, where inhibitors of serotonin uptake measurably enhance and prolong serotonin-mediated excitatory postsynaptic potentials (EPSPs) in a postsynaptic neuron (Gershenfeld et al., 1978) and (2) lamprey medullary Müller cells, where both GABA- and glycineevoked IPSPs were prolonged during uptake-suppressing conditions, such as reduced sodium concentration (Matthews and Wickelgren, 1979). These effects are consistent with a role for uptake in the physiological dynamics of synaptic transmission.

One of the most compelling evidences for glycine as a neurotransmitter is the unique association of high affinity transport with specific retinal neurons (Chin and Lam, 1980). It is possible that glycine is not the endogenous transmitter for neurons that we identify by autoradiography of $\left[{ }^{3} \mathrm{H}\right]$ glycine uptake. If not, then high intrinsic levels of glycine in neural tissue might make glycine an effective endogenous competitor for the actual neurotransmitter. Alternatively, glycine could be an essential precursor for the actual neurotransmitter. Since there is 


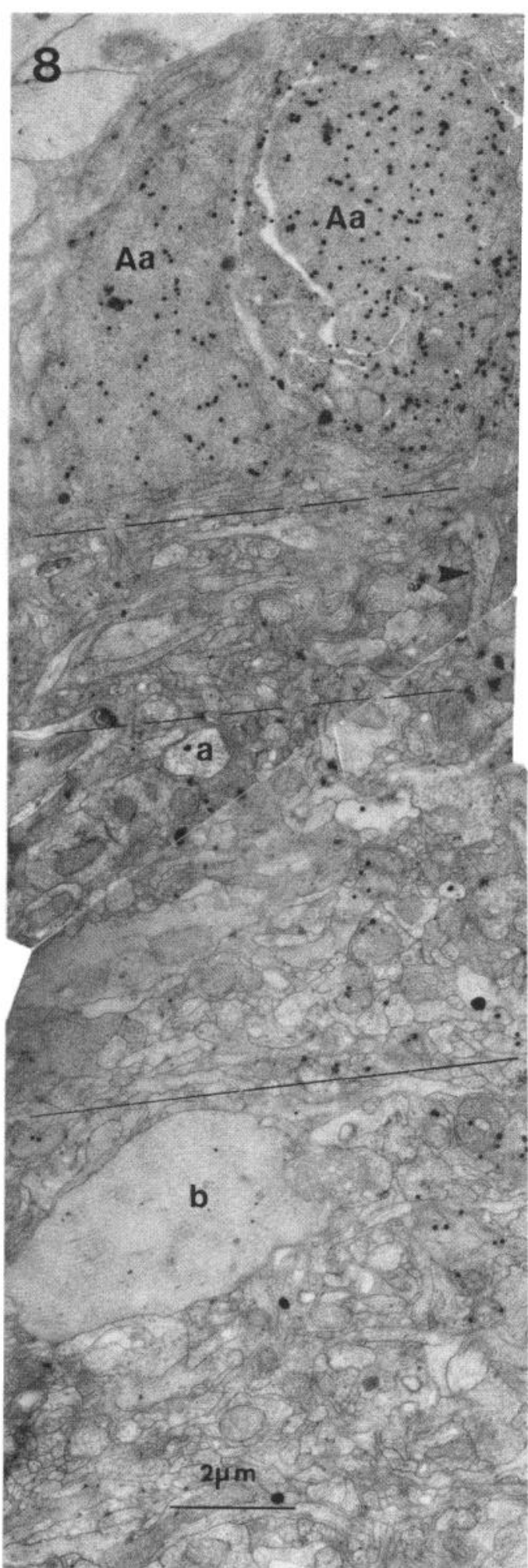

Figure 8. $\left[{ }^{3} \mathrm{H}\right] \mathrm{Glycine}$ uptake by Aa ACs (EM-ARG). Two labeled $\mathrm{A} a$ ACs $(A a)$ are shown closely apposed. The labelpoor "gap" is indicated by dashed lines and the proximal stalk of the right hand $\mathrm{A} a \mathrm{AC}$ is indicated by the arrow. Sublaminas $a$ and $b$ are separated by a solid line.

no direct evidence to support these views, it would seem parsimonious to consider neurons possessing high affinity glycine uptake as glycinergic. Certainly our identification of $\mathrm{H} 1 \mathrm{HCs}$ as GABAergic gives us confidence that high affinity uptake systems are useful for neurotransmitter classification.

Stimulus-evoked alterations in neurotransmitter uptake. Our results show, once again, that photic conditions can influence the efficacy with which radiolabeled transmitter candidates are accumulated by high affinity uptake into some cell types. In accord with our previous findings (Lam and Steinman, 1971; Marc et al., 1978; Marc, 1980), conditions which tend to hyperpolarize neurons enhance observed uptake and depolarizing conditions suppress observed uptake. Martin (1976) has proposed a relationship between steady state transmembrane neurotransmitter gradients and membrane potential that describes exactly such a relationship. Some possible mechanisms contributing to voltage-influenced
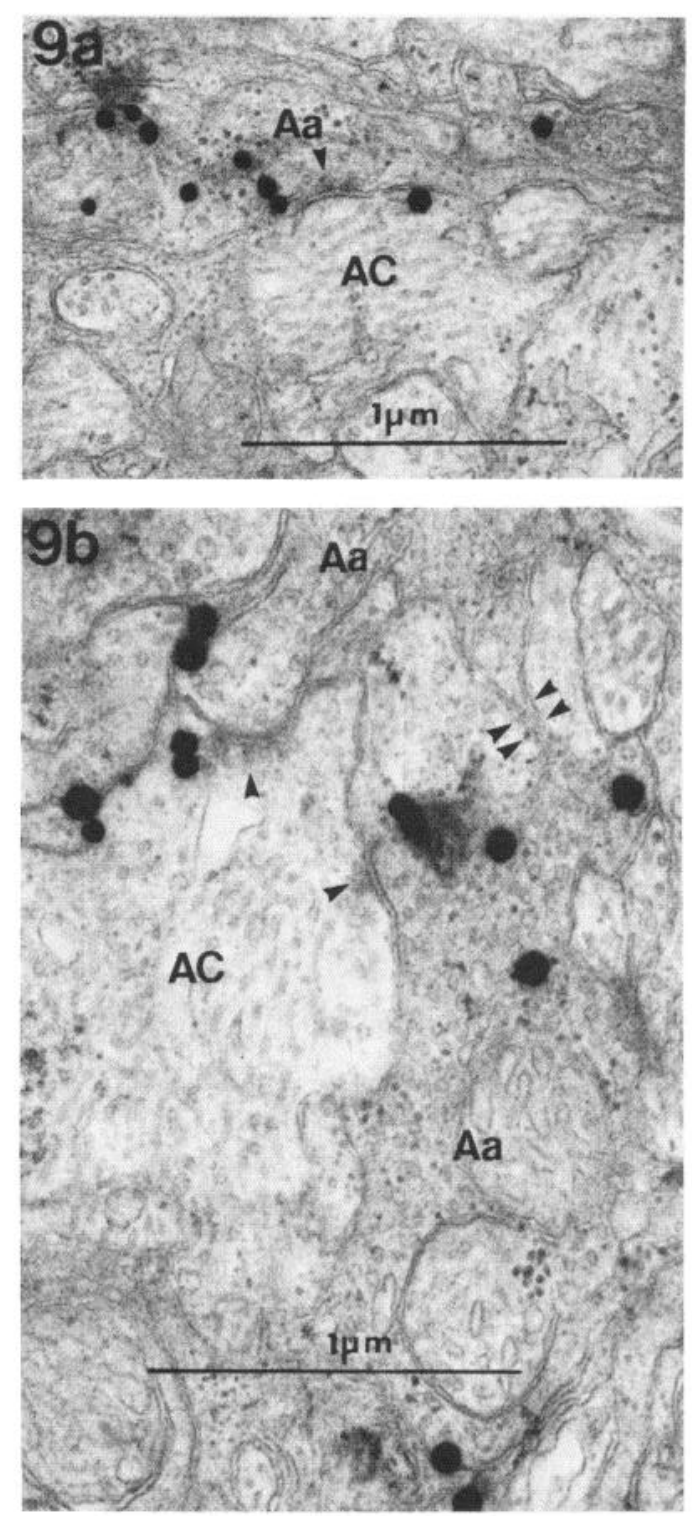

Figure 9. Synapses of $\left[{ }^{3} \mathrm{H}\right]$ glycine-labeled profiles in the IPL (EM-ARGs). $a$, A labeled, glycogen-containing profile $(A a)$ making a conventional synapse (arrow) onto an electron-lucent profile assumed to be an AC. $b$, A labeled profile $(A a)$ that makes a narrow bridge (double arrows) to curve around a pale profile from which it receives two conventional synapses (arrows). 


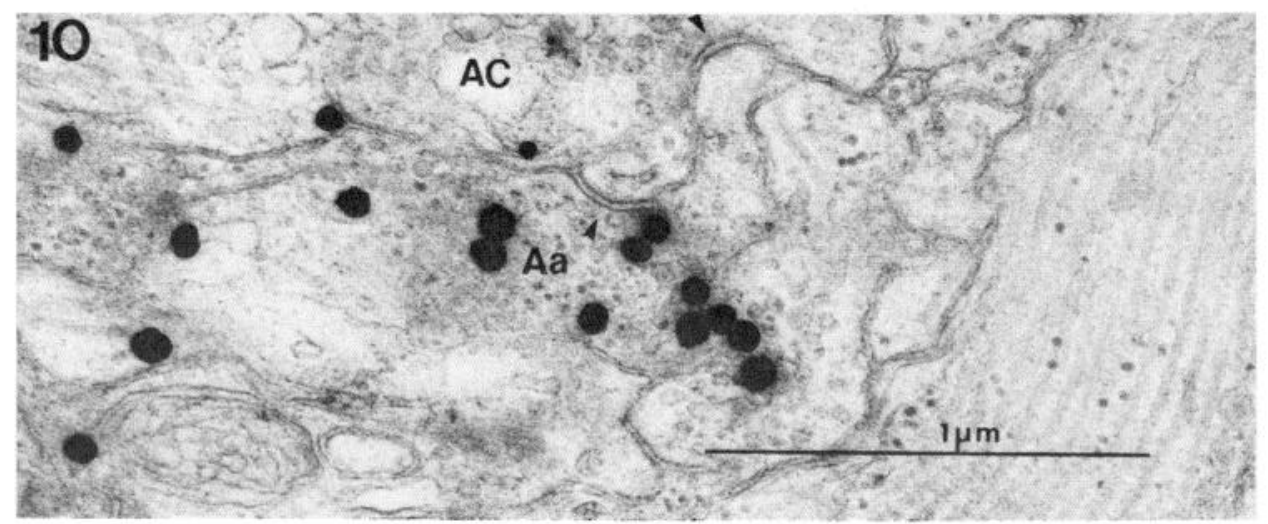

Figure 10. Reciprocal synapse between a labeled profile $(A a)$ and another AC (EMARG). A well labeled, glycogen-containing profile is shown making a synapse upon an AC (upward arrow) and receiving a conventional synapse from the same process at a site about $300 \mathrm{~nm}$ away.

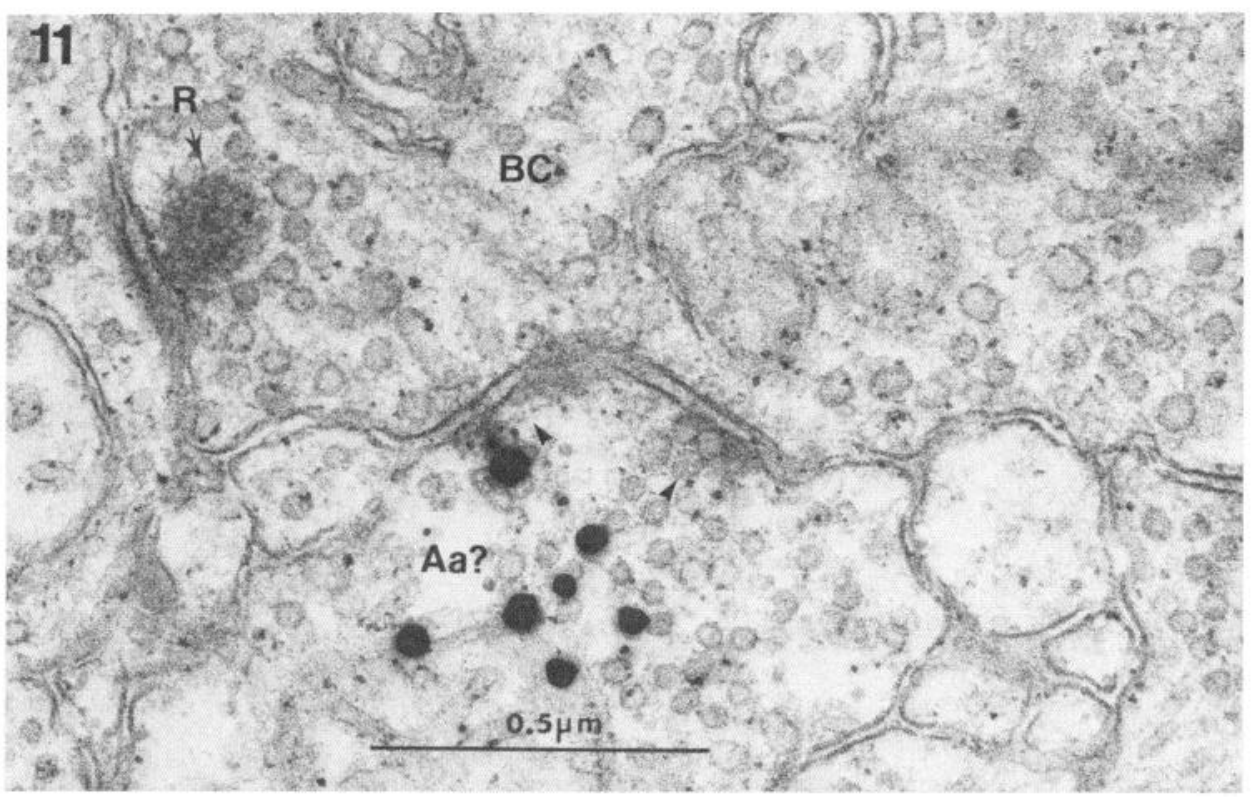

Figure 11. Conventional synapse from a labeled profile $(A a)$ onto a BC terminal (EMARG). A large synapse, cut obliquely in the center, is indicated by two arrows. $R$, en face cut $\mathrm{BC}$ ribbon. En bloc uranyl acetate stain. Since no glycogen is present, the characterization $\mathrm{A} a$ is tentative.

catecholamine uptake have been reviewed by White (1976). Lam and Ayoub (D. M. K. Lam and G. S. Ayoub, manuscript in preparation) have shown that the transmembrane potential directly influences the efficiency of GABA uptake in $\mathrm{H} 1 \mathrm{HCs}$ such that progressively increasing transmembrane depolarization leads to graded decreases in the rate of GABA uptake. This suppression of uptake is independent of release (see also Blaustein and King, 1976).

An important feature of voltage-influenced uptake is that the net uptake observed under our incubation conditions will be influenced by several factors, such as the slope of the uptake-maintained transmitter gradient versus membrane potential function, the absolute "dark" potential, the magnitudes of light-evoked potential changes, the time integral of the light-evoked voltage responses, and transmitter release rates. Release accounts for little of our observed changes because net uptake is assessed in the presence of "probe" concentrations of neurotransmitter which are continually being diluted into a large intracellular volume, and less than half of that accumulated by somas is releasable when exposed to $40 \mathrm{mM} \mathrm{K}^{+}$for 10 min (Figs. 6 and 7).

Glycine release in the goldfish retina. Chin and Lam (1980) have reported that elevated extracellular potassium levels can evoke release of preloaded $\left[{ }^{3} \mathrm{H}\right]$ glycine from goldfish retinas. We have replicated that result here. Our quantitation of release is based upon loss of label from $\mathrm{AC}$ somas rather than terminals. The geometry of the neuropil precludes useful light microscope quantitation of such data within the IPL. It is worth noting, however, that grain clusters indicative of $\mathrm{A} a \mathrm{AC}$ 

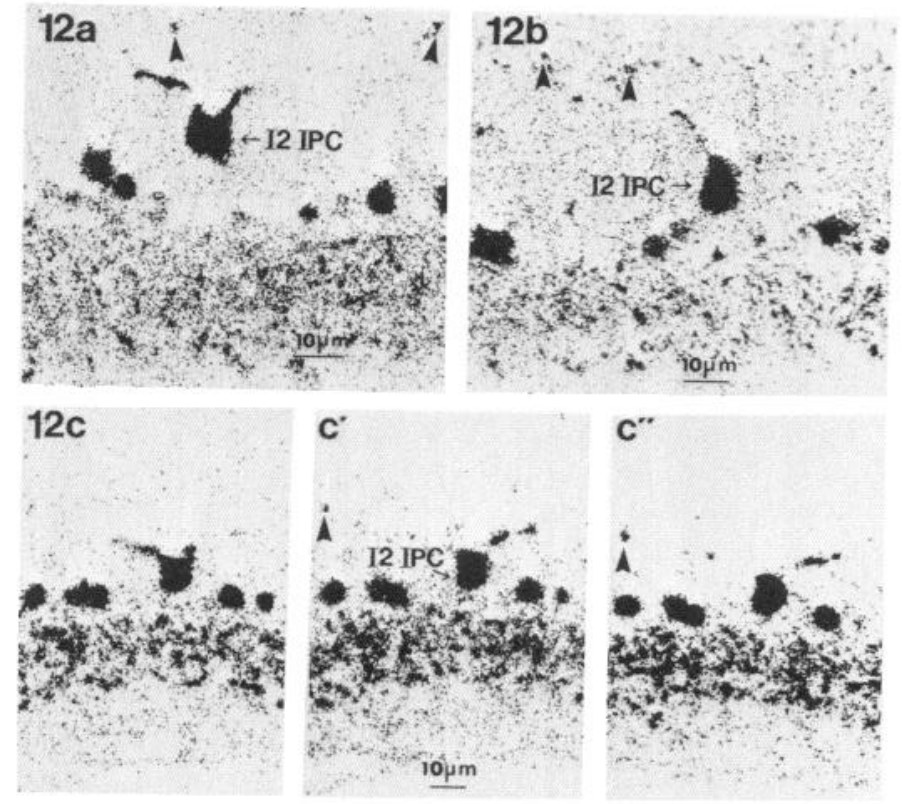

Figure 12. Somas of $\left[{ }^{3} \mathrm{H}\right]$ glycine-accumulating I2 IPCs (LMARGs). Each I2 IPC appears to have a few (usually a pair) of thick, distally directed dendrites. Upward arrows indicate $I 2$ IPC terminals in the OPL. $a$ and $b$, Two I2 IPCs with distal dendrites; $500 \mu \mathrm{Ci} / \mathrm{ml}$; 7-day exposure. $c^{\prime}$, and $c^{\prime \prime}$, Three serial $2-\mu \mathrm{m}$ sections showing a pair of dendrites arising from an $I 2$ IPC; $1 \mathrm{mCi} / \mathrm{ml}$; 14-day exposure.

presynaptic terminals disappear from preloaded preparations treated with high potassium salines, but not those treated with normal salines (Fig. 6). That depolarizing conditions lead to measurable somatic label losses is not unprecedented (see Marc et al., 1978). We conclude that, under these harsh depolarizations, neurotransmitter is scavenged as rapidly as possible from intracellular stores, including some somatic stores, for release at the terminals. While ionically evoked release is not necessarily evidence of physiological release, it is definitely consistent with the view that glycine-accumulating retinal neurons are glycinergic.

Glycinergic $A$ a $A C$ s in the goldfish retina. The spectral responsivity and morphology of $\mathrm{A} a$ ACs makes them likely candidates for the red-hyperpolarizing, sustained ACs identified electrophysiologically in cyprinid retinas. In such electrophysiological studies, most of the "sustained" ACs reported have been $-\mathrm{R} /+\mathrm{G}$ cells (e.g., Kaneko, 1973), that is, red-hyperpolarizing/green-depolarizing cells. This is in agreement with the observation that putative $-\mathrm{R} /+\mathrm{G}$ glycinergic $\mathrm{A} a \mathrm{ACs}$ outnumber $+\mathrm{R} /-\mathrm{G}$ GABAergic A $b$ ACs by 12 to 1 (R. E. Marc, manuscript in preparation). Dye injection studies reveal sustained red-hyperpolarizing $\mathrm{ACs}$ to be small cells ramifying primarily in sublamina $a$ (Famiglietti et al., 1977).

$\mathrm{A} a \mathrm{ACs}$ received inputs from and have outputs to $\mathrm{ACs}$, notably engaging in reciprocal synapses (Fig. 17). Exogenously applied glycine has been shown to have a suppressive effect on spiking activity in both on and off center GCs of carp retina (Negishi et al., 1978). No evidence has been accrued to indicate whether carp GCs are influenced directly by glycine, but glycine-induced hyperpolarizations of some transient GCs in the mud puppy retina have been shown to persist after perfusion with sufficient $\mathrm{Co}^{2+}$ to make the GC unresponsive to light (Miller et al., 1977). Some of our Aa AC processes might contact GCs.
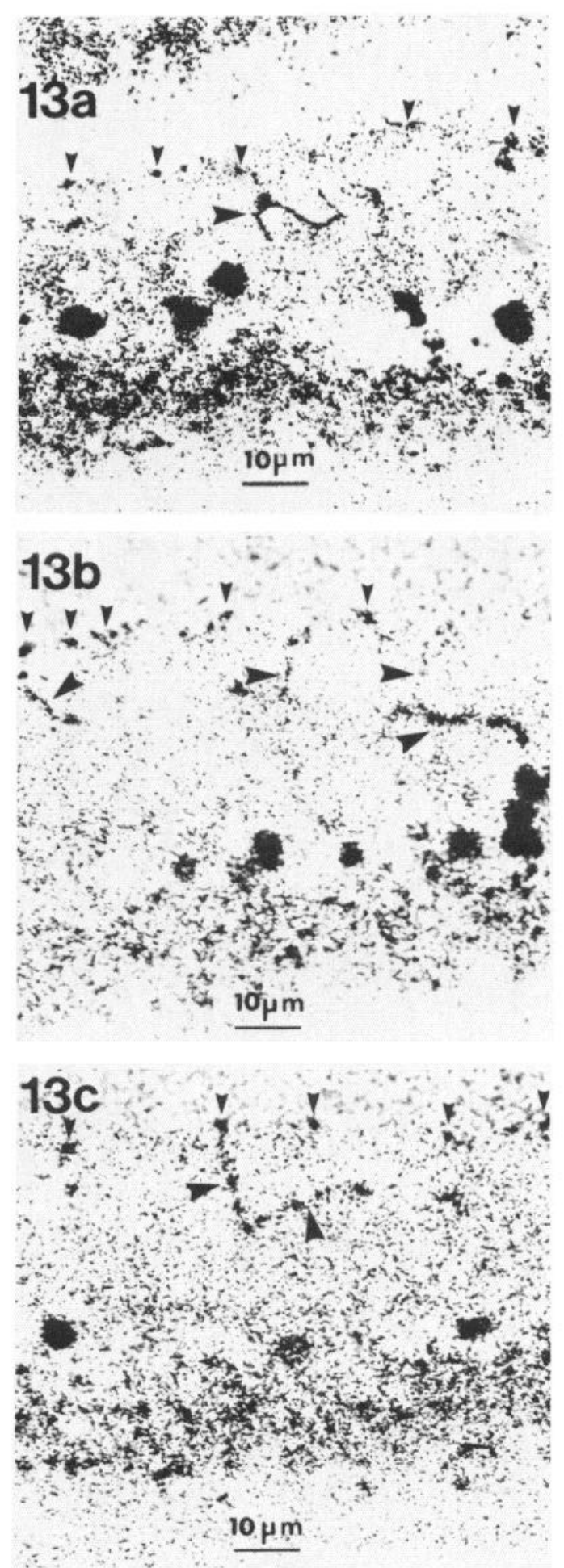

Figure 13. Patterns of $I 2$ dendrites in the INL and OPL (LM-ARGs). I2 IPC terminals, small arrows; I2 IPC dendrites, large arrows. $a$, A complex I2 IPC dendrite in the INL. $b$, A series of small I2 IPC dendrites rising to the OPL, one of which appears to branch from a thick dendrite at right. $c, \mathrm{~A}$ bifurcating dendrite clearly connected to a terminal in the OPL. 
There is a superficial correlation between the locus of glycine uptake into A $a$ ACs and its possible effects on BCs. While both on and off center GCs in carp are influenced by glycine (Negishi et al., 1978), mud puppy off center BCs (center hyperpolarizing) are more strongly

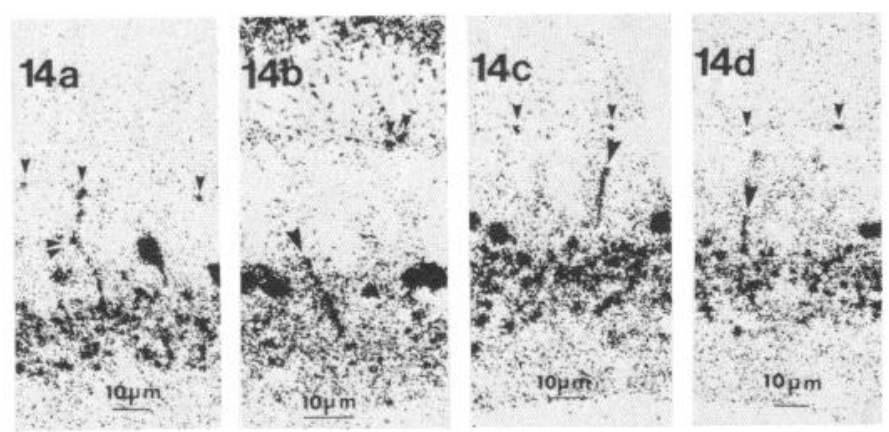

Figure 14. I2 IPC processes traversing the INL to connect the OPL and IPL (LM-ARGs). I2 IPC terminals, small arrows; I2 IPC connecting processes, double arrows and large arrows. $a$, A single, continuous I2 IPC process connecting the IPL and OPL. It apparently arises from a large dendrite in the INL that bifurcates at the point indicated by double arrows. $b, c$, and $d$, Three connecting processes at various levels in the INL and IPL. influenced by glycine than are on center BCs (Miller et al., 1977). Our morphological data indicate that if such a neurochemical pathway were a generalized ectotherm circuit, it must be polysynaptic for the majority of off center BCs. A $a$ ACs await more thorough morphological analysis, e.g., serial section EM-ARGs and double label experiments. At this point, it is important to note that, while we can identify certain labeled profiles in the IPL as A $a$ ACs with some confidence, we do not know to what degree I2 IPCs influence physiologically characterized glycine-mediated events in the IPL.

Glycinergic I2 IPCs in the goldfish retina. Glycinergic I2 IPCs constitute the first case of physiologically distinguishable subsets of IPCs. Gallego (1971) introduced the term "interplexiform cell" but declined an explicit definition. We argue that any neuron that has processes in both the OPL and IPL but receives no photoreceptor input is an interplexiform cell; this definition presumes no directionality of signal transmission. Thus, it is clear that the goldfish retina contains both dopaminergic and glycinergic IPCs. Each possesses distinctive morphological, connective, chemical, and presumably, electrophysiological traits. Multiple types of IPCs in a single retina are not unexpected. Amine-containing I1 IPCs were first characterized in the perch retina (Ehinger et al., 1969), yet Ramón y Cajal (1892) drew Golgi-impregnated perch
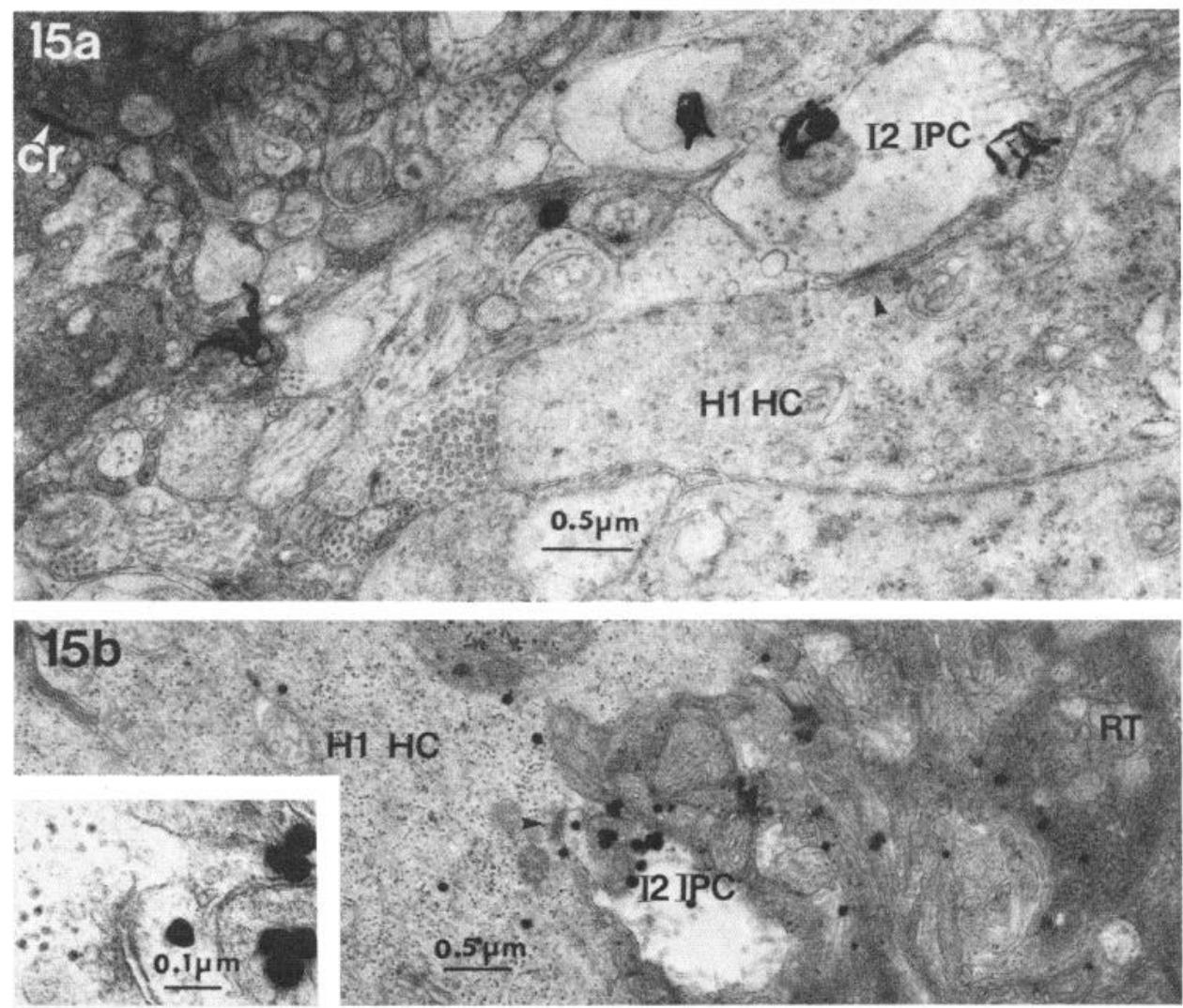

Figure 15. Horizontal cell synapses onto I2 IPCs (EM-ARGs). a, A process possessing the characteristic pale intracellular matrix of an I2 IPC receives a conventional synapse from the basal portion of a type $\mathrm{H} 1 \mathrm{HC}$ dendrite. The process is in contact with two silver grains, labeling is too sparse to identify clearly the profile. $\mathrm{Cr}$, cone synaptic ribbon. $b, \mathrm{~A}$ conventional synapse for the soma of a type $\mathrm{H} 1 \mathrm{HC}$ onto a heavily labeled I2 IPC profile. The synapse (arrow) is enlarged in the inset. $R T$, rod terminal. 

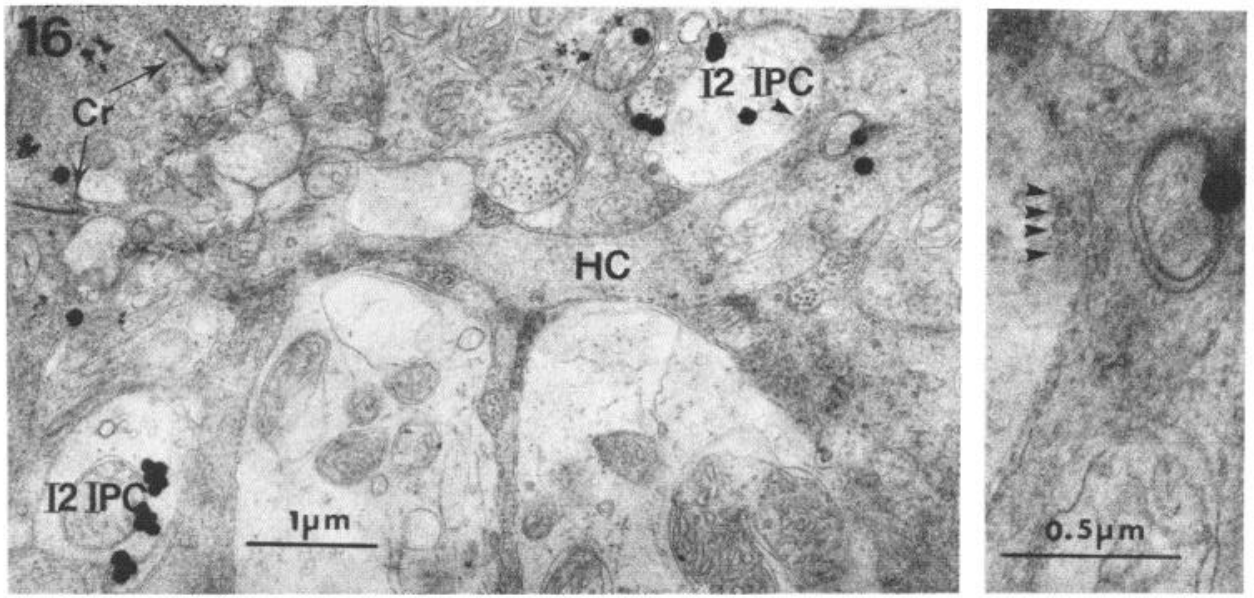

Figure 16. A possible I2 IPC synapse onto a horizontal cell (EM-AGR). Two labeled, characteristically pale I2 IPC processes appear near the obliquely sectioned $I 2$ IPC/HC boundary. The vesicle cluster is enlarged at right (multiple arrows). $\mathrm{Cr}$, cone synaptic ribbon.

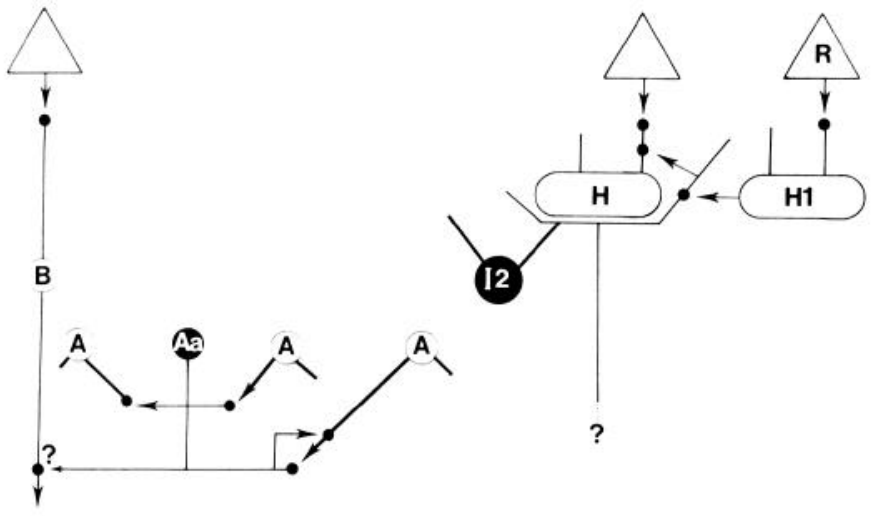

Figure 17. A summary of possible synaptic connections made by putative glycinergic $\mathrm{A} a \mathrm{ACs}$ and $I 2$ IPCs. $\mathrm{A} a \mathrm{ACs}(A a)$ make conventional synapses upon (arrows) and receive conventional synapses from (solid circles) one or more types of ACs $(A)$ whose identities are unknown. Some labeled profiles also make infrequent synapses upon small axon terminals of some type of $\mathrm{BC}$ in the middle of the IPL. We cannot be certain whether they are from $\mathrm{A} a \mathrm{ACs}$ or I2 IPCs. The BC terminals are probably not those of mixed rod-cone BCs. I2 IPCs clearly receive conventional synapses on their dendrites from somas of red cone-dominated $\mathrm{H} 1 \mathrm{HCs}$ and might be presynaptic to the dendrites of unidentified HCs in the OPL. The IPL connections of $I 2$ IPCs are completely unknown. Triangles indicates cones; $R$, red-sensitive cone.

IPCs that were unequivocally not the kind revealed by amine-induced fluorescence. Finally, Oyster and Takahashi (1977) delineated three possible morphological subtypes of rabbit IPCs in a Golgi impregnation study.

Over the years, there have been many studies of the effects of glycine in the cyprinid OPL, primarily concerning cone $\mathrm{HCs}$, but the results are variable: some workers reported that glycine hyperpolarized some cone HCs in carp (Murakami et al., 1972; Sugawara and Negishi, 1973a, b; Wu and Dowling, 1980), while Negishi and Drujan (1979) showed primarily depolarization by glycine in cone HCs of the teleost Eugerres $s p$. In some cone
HCs, glycine effects could not be elicited at all (e.g., Murakami et al., 1978). These results suggest that the effects of exogenously applied glycine depend upon uncontrolled variables.

While some glycine-mediated influences in the OPL may be polysynaptic in origin, the presence of glycineaccumulating $I 2$ IPCs provides a cogent mechanism for some direct effects. I2 IPCs are likely to be presynaptic to cone $\mathrm{HC}$ dendrites in the OPL and are postsynaptic to the somas of H1 HCs (Fig. 17). The sparseness of I2 IPC terminals (about $5 / \mathrm{H} 1 \mathrm{HC}$, which translates to roughly 10/C-type HC) makes one question the strength of glycinergic influences in the OPL. We believe that an explanation for the sparseness may be that I2 IPCs are presynaptic to $\mathrm{HC}$ dendrites and not $\mathrm{HC}$ somas. Since each type of cone $\mathrm{HC}$ is electrotonically coupled by gap junctions to HCs of its own class (Norton et al., 1968; Witkovsky and Dowling, 1969; Marc et al., 1978), the low somatic input resistance would preclude a few synapses from dramatically altering the membrane potential of $\mathrm{HC}$ somas under normal circumstances. It is worth noting that dopaminergic I1 IPCs have at least an order of magnitude more OPL synaptic terminals than I2 IPCs (R. E. Marc, manuscript in preparation) and these are situated mostly on the somas of H1 HCs. I2 IPC synapses strategically placed on $\mathrm{HC}$ dendrites could conceivably modulate the conductance of a patch of dendrite so as to alter its local cable constants (Jack et al., 1975) and thereby control dendritic signal transmissability without necessarily influencing somatic transmembrane potential. On the whole, the weak influences of massive quantities of glycine (5 to $10 \mathrm{~mm}$ ) applied in most electrophysiological experiments attests to the plausibility of such a mechanism. If, as we suppose, the postsynaptic ionic mechanisms controlled by glycine are poised near the reversal potential, future studies of glycinergic mechanisms in the OPL must include reliable data on absolute membrane potentials.

One role of I2 IPCs may be to contribute to or modulate red-induced depolarizations of color opponent $+R$ / -G H2 HCs in the carp retina. Wu and Dowling (1980) 
have reported that nebulizer-applied glycine hyperpolarizes the membranes and selectively suppresses the long wavelength responses of some $\mathrm{H} 2 \mathrm{HCs}$. If IPCs do mediate these events, then they must receive some reddominated inputs. Regardless of the nature of I2 IPC connections in the IPL, glycinergic I2 IPCs receive conventional synapses from the somas of red-hyperpolarizing $\mathrm{H} I \mathrm{HCs}$. Whatever the nature of the $\mathrm{HC}$ dendrites upon which I2 IPCs appear to synapse or the sign of the synapse, the I2 IPCs will obviously transmit some red signals. We stress that the scarcity of I2 IPC terminals in the OPL leads us to propose that glycinergic events in OPL are primarily modulatory in nature. The origin of red depolarization in $\mathrm{H} 2 \mathrm{HCs}$ is, in our view, still driven primarily by $\mathrm{H} 1 \mathrm{HC} \rightarrow$ green cone $\rightarrow \mathrm{H} 2 \mathrm{HC}$ transmission (Stell and Lightfoot, 1975; Stell et al., 1975; Marc et al., 1978; Murakami et al., 1978).

The identification of the recipients of synapses from $\mathrm{H} 1 \mathrm{HCs}$ (formerly called external HCs or EHCs) is of more than passing interest. $\mathrm{H} 1 \mathrm{HC}$ synapses onto unknown processes in the OPL have been well characterized morphologically (Witkovsky and Dowling, 1969); Dowling and Ehinger (1978) noted H1 HC synapses were clearly not made on dopaminergic $I 1$ IPC terminals. Since glycinergic I2 IPCs are postsynaptic at some (perhaps all) H1 HC somatic synapses, we must now admit that the concept of the IPC is apparently one which can no longer be ignored in circuit models and that $\mathrm{HCs}$ are themselves more complex than many of us have previously suspected.

We have no knowledge of the connections of $I 2$ IPCs within the IPL. The geometry of I2 IPC synaptic connections in the OPL does raise the question of whether their somas will accurately reflect electrical events in dendritic arbors of either plexiform layer. Conventional histological methods, such as electron microscopy of Golgi-impregnated neurons possessing the morphology of $I 2$ IPCs, clearly will have much to contribute to our understanding of this novel class of retinal cells.

\section{References}

Aprison, M. H., and N. S. Nadi (1978) Glycine: Inhibition from the sacrum to the medulla. In Amino Acids as Chemical Transmitters, F. Fonnum, ed., pp. 531-570, Plenum Press, New York.

Aprison, M. H., and R. Werman (1965) The distribution of glycine in cat spinal cord and roots. Life Sci. 4: 2075-2083.

Bok, D., and R. W. Young (1972) The renewal of diffusely distributed protein in the outer segments of rods and cones. Vision Res. 12: 161-168.

Blaustein, M. P., and A. C. King (1976) Influence of membrane potential on the sodium-dependent uptake of gamma-aminobutyric acid by pre-synaptic nerve terminals: Experimental observations and theoretical considerations. J. Membr. Biol. 30: 153-173.

Chin, C. -A., and D. M. K. Lam (1980) The uptake and release of $\left[{ }^{3} \mathrm{H}\right]$-glycine in the goldfish retina. J. Physiol (Lond.) 308 : in press.

Curtis, D. R., L. Hösli, G. A. R. Johnston, and I. H. Johnson (1968) The hyperpolarization of spinal interneurons by glycine and related amino acids. Exp. Brain Res. 5: 235-258.

Dowling, J. E., and B. Ehinger (1975) Synaptic organization of the amine-containing interplexiform cells of the goldfish and Cebus monkey retinas. Science 188: 270-273.
Dowling, J. E., and B. Ehinger (1978) The interplexiform cell system I. Synapses of the dopaminergic neurons of the goldfish retina. Proc. R. Soc. Lond. (Biol.) 207: 7-26.

Ehinger, B., B. Falck, and A. M. Laties (1969) Adrenergic neurons in teleost retina. Z. Zellforsch. Mikrosk. Anat. 97: 285-297.

Famiglietti, E. V., Jr., A. Kaneko, and M. Tachibana (1977) Neuronal architecture of on and off pathways to ganglion cells in carp. Science 198: 1267-1269.

Gallego, A. (1971) Horizontal and amacrine cells in the mammal's retina. Vision Res. Suppl 3: 33-50.

Gerschenfeld, H. M., M. Hamon, and D. Paupardin-Tritsch (1978) Release of endogenous serotonin from two identified serotonin-containing neurons and the physiological role of serotonin re-uptake. J. Physiol (Lond.) 274: 265-278.

Graham, L. T., R. P. Shank, R. Werman, and M. H. Aprison (1967) Distribution of some synaptic transmitter candidates in cat spinal cord: Glutamic acid, aspartic acid, $\gamma$-aminobutyric acid, glycine and glutamine. J. Neurochem. 14: 465-472.

Hökfelt, T., and A. Ljungdahl (1971) Light and electron microscope autoradiography on spinal cord slices after incubation with labeled glycine. Brain Res. 32: 189-194.

Iversen, L. (1971) Role of transmitter uptake mechanisms in synaptic neurotransmission. Br. J. Pharmacol. 41: 571-59l.

Jack, J. J. B., D. Noble, and R. W. Tsien (1975) Electric Current Flow in Excitable Cells. Clarendon Press, Oxford.

Kaneko, A. (1973) Receptive field organization of bipolar and amacrine cells in the goldfish retina. J. Physiol. (Lond.) 235: 133-153.

Lam, D. M. K. (1975) Biosynthesis of $\gamma$-aminobutyric acid by isolated axons of cone horizontal cells in the goldfish retina. Nature 254: 345-347.

Lam, D. M. K., and L. Steinman (1971) The uptake of $\gamma-\left[{ }^{3} \mathrm{H}\right]-$ aminobutyric acid in the goldfish retina. Proc. Natl. Acad. Sci. U. S. A. 68: 2777-2781.

Lam, D. M. K., E. M. Lasater, and K. -I. Naka (1978) $\gamma$ Aminobutyric acid: A neurotransmitter candidate for cone horizontal cells of the catfish retina. Proc. Natl. Acad. Sci. U. S. A. 75: 6310-6313.

Lam, D. M. K., Y. Y. T. Su, L. Swain, R. E. Marc, C. Brandon, and J. - Y. Wu (1979) Immunocytochemical localization of Lglutamic acid decarboxylase in the goldfish retina. Nature 278: 565-567.

Marc, R. E. (1980) Retinal colour channels and their neurotransmitters. In Colour Deficiencies $V$, Institute of Physics, London.

Marc, R. E., W. K. Stell, D. Bok, and D. M. K. Lam (1978) GABA-ergic pathways in the goldfish retina. J. Comp. Neurol. 182: 221-245.

Martin, D. L. (1976) Carrier-mediated transport and removal of GABA from synaptic regions. In GABA in Nervous System Function, E. Roberts, T. N. Chase, and D. Tower, eds., pp. 377-386, Raven Press, New York.

Martin, R. J. (1979) Glycine and GABA induced conductance changes in lamprey reticulospinal neurons and their antagonism by strychnine, thebaine, bicuculline and picrotoxin. Comp. Biochem. Physiol. (C) 63: 109-115.

Matthews, G., and W. O. Wickelgren (1979) Glycine, GABA and synaptic inhibition of reticulospinal neurons of lamprey. J. Physiol. (Lond.) 293: 393-415.

Matus, I. I., and M. E. Dennison (1972) An autoradiographic study of uptake of exogenous glycine by vertebrate spinal cord slices in vitro. J. Neurocytol. 1: 27-34.

Miller, R. F., R. F. Dacheux, and T. E. Frumkes (1977) Amacrine cells in Necturus retina: Evidence for independent $\gamma$ aminobutyric acid and glycine-releasing neurons. Science 198: 748-750.

Murakami, M., K. Ohtsu, and T. Ohtsuka (1972) Effects of 
chemicals on receptors and horizontal cells in the retina. $J$ Physiol. (Lond.) 227: 899-913.

Murakami, M., Y. Shimoda, and K. Nakatani (1978) Fffects of GABA on neuronal activities in the distal retina of the carp. Sens. Processes 2: 334-338.

Negishi, K., and B. D. Drujan (1979) Effects of some amino acids on horizontal cells in the fish retina. J. Neuroscience Res. 4: 351-363.

Negishi, K., S. Kato, T. Teranishi, and M. Laufer (1978) Dual actions of some amino acids on spike discharges in the carp retina. Brain Res. 148: 67-84.

Norton, A. L., H. Spekreijse, M. Wolbarsht, and H. G. Wagner (1968) Receptive-field organization of the S-potential. Science 160: 1021-1022.

Oxender, D. L., and H. N. Christensen (1963) Distinct mediating systems for the transport of neutral amino acids by the Ehrlich cell. J. Biol. Chem. 238: 3686-3699.

Oyster, C. W., and E. S. Takahashi (1977) Interplexiform cells in rabbit retina. Proc. R. Soc. Lond. Biol. 197: 477-484.

Ramón y Cajal, S. (1892) La retine des vertebres. Cellule 9: 121-246.

Rayborn, M., P. V. Sarthy, J. G. Hollyfield, and D. M. K. Lam (1980) The emergence, localization and maturation of neurotransmitter systems during development of the retina in Xenopus laevis. II. Glycine. J. Comp. Neurol., in press.

Stell, W. K., and D. O. Lightfoot (1975) Color-specific interconnections of cones and horizontal cells in the retina of the goldfish. J. Comp. Neurol. 159: 473-502.
Stell, W. K., D. O. Lightfoot, 'I'. G. Wheeler, and H. F. Leeper (1975) Goldifsh retina: Functional polarization of horizontal cell dendrites and synapses. Science 190: 989-990.

Sugawara, K., and K. Negishi (1973a) Effects of some amino acids on the horizontal cell membrane potential in the isolated carp retina. Vision Res. 13: 977-981.

Sugawara, K., and K. Negishi (1973b) Effects of some amino acids on light-induced responses in the isolated carp retina. Vision Res. 13: 2479-2489.

Tebécis, A. K., and A. DiMaria (1972) Strychnine-sensitive inhibition in the medullary reticular formation: Evidence for glycine as an inhibitory transmitter. Brain Res. 40: 373-383.

Werman, R., R. A. Davidoff, and M. H. Aprison (1967) Inhibition of motoneurones by iontophoresis of glycine. Nature 214: 681-683.

Werman, R., R. A. Davidoff, and M. H. Aprison (1968) Inhibitory action of glycine on spinal neurons in the cat. J. Neurophysiol. 31:81-95.

White, T. D. (1976) Models for neuronal noradrenalin uptake. In The Mechanism of Neuronal and Extraneuronal Transport of Catecholamines, D. A. Paton, ed., pp. 175-193, Raven Press, New York.

Witkovsky, P., and J. E. Dowling (1969) Synaptic relationships in the plexiform layers of the carp retina. Z. Zellforsch. Mikrosk. Anat. 100: 60-82.

Wu, S. M., and J. E. Dowling (1980) Effects of GABA and glycine on the distal cyprinid retina. Brain Res., 199: 401404 . 